\title{
The Neutrophil-Lymphocyte Ratio has Little Impact on Survival in Breast Cancer Patients Treated with Neoadjuvant Chemotherapy Followed by Surgery
}

\section{Katsuhisa Enomoto}

Nihon University Itabashi Hospital: Nihon Daigaku Igakubu Fuzoku Itabashi Byoin

\section{Satsuki Fukumoto}

Nihon University Itabashi Hospital: Nihon Daigaku Igakubu Fuzoku Itabashi Byoin

Hironori Goto

Nihon University Itabashi Hospital: Nihon Daigaku Igakubu Fuzoku Itabashi Byoin

\section{Satoshi Mori}

Nihon University Itabashi Hospital: Nihon Daigaku Igakubu Fuzoku Itabashi Byoin

\section{Yukiko Hara}

Nihon University Itabashi Hospital: Nihon Daigaku Igakubu Fuzoku Itabashi Byoin

Keiichiro Tada ( $\nabla$ tada.keiichiro@nihon-u.ac.jp )

Nihon University Itabashi Hospital: Nihon Daigaku Igakubu Fuzoku Itabashi Byoin https://orcid.org/0000-0002-5395-986X

\section{Research Article}

Keywords: Breast neoplasm, neutrophil-lymphocyte ratio, disease-free survival

Posted Date: May 11th, 2021

DOl: https://doi.org/10.21203/rs.3.rs-486023/v1

License: (c) (i) This work is licensed under a Creative Commons Attribution 4.0 International License. Read Full License 


\section{Abstract}

Background: The impact of the neutrophil-lymphocyte ratio (NLR) on the survival outcomes of patients with early-stage breast cancer is controversial.

Methods: We reviewed a series of 115 breast cancer patients who received neoadjuvant chemotherapy followed by surgical treatment. The NLR was calculated using a blood sample obtained before neoadjuvant chemotherapy. The relationships of disease-free survival with the NLR as well as other clinicopathological factors were assessed.

Results: There was no significant association between the NLR and disease-free survival in these patients. On the other hand, negative estrogen receptor and progesterone receptor statuses, extended nodal involvement, and advanced TNM stage were significant predictors of shorter disease-free survival.

Conclusions: The NLR has little impact on the survival of early-stage breast cancer patients treated with neoadjuvant chemotherapy followed by surgical treatment.

\section{Background}

Breast cancer is the fourth leading cause of cancer-related death worldwide, and approximately 600,000 people were estimated to have died from breast cancer in 2018 [1]. Decreasing this mortality rate is mandatory. Recent advances in adjuvant chemotherapy have improved the survival outcomes of patients with early-stage breast cancer [2]. However, adjuvant chemotherapy potentially causes fatal adverse effects [3]. Accordingly, the patients appropriate for this treatment should be selected properly. When assessing the indications for adjuvant chemotherapy, the expression status of specific biomarkers such as the estrogen receptor (ER) and human epidermal growth factor receptor 2 (HER2) is evaluated initially. Next, the nodal status and expression status of specific genes in cancer tissues, such as those assessed by the 21-gene recurrence score assay [4], are determined. Other indicators include tumor size, progesterone receptor ( $\mathrm{PgR}$ ) status, ki67 expression, and the nuclear grade. To identify patients with earlystage breast cancer who are most suitable for adjuvant chemotherapy, better risk factors for breast cancer mortality are needed.

The neutrophil-lymphocyte ratio (NLR) is a prognostic marker, the utility of which has been evaluated previously [5-7]. The NLR is believed to reflect the immunological status of patients. The advantage of this marker is that it is relatively easy to determine via blood tests. Although some studies have reported that the NLR is a useful prognostic factor [8-12], the value of this marker in early-stage breast cancer is controversial [13].

Here, we evaluated whether the NLR is a useful prognostic factor for early-stage breast cancer. We examined the relationship between the NLR and disease-free survival among early-stage breast cancer patients who received neoadjuvant chemotherapy in our institution. 


\section{Methods}

We searched our department database for early-stage breast cancer patients who received neoadjuvant chemotherapy between May 2014 and August 2018. The medical charts of these patients were reviewed, and the following data were obtained: age, clinical stage, pathological data, blood laboratory data including the NLR, the surgical and postoperative treatments received, and survival time. The survival status of the patients was updated in September 2020.

The continuous data were analyzed by Student's t test or, if the data did not follow a normal distribution, the Mann-Whitney U test. The categorical data were analyzed by Fisher's exact test. Disease-free survival rates were calculated using the Kaplan-Meier method and compared using the log rank test. Cox proportional hazards models were used to evaluate the association of disease-free survival with the NLR, compared with other known prognostic factors. A P value $<0.05$ was considered significant. All statistical analyses were performed using the statistical package R v4.0.3 (R Foundation for Statistical Computing, Vienna, Austria; ISBN 3-900051-07-0; http://www.R-project.org).

\section{Results}

Between May 2014 and August 2018, 1,110 breast cancer patients underwent surgical treatment at our institution, of whom $115(10.4 \%)$ received neoadjuvant chemotherapy. The median follow-up period was 39 months (range: 8-75 months). During the follow-up period, 25 cases of recurrence occurred.

The clinicopathological characteristics of the 115 patients according to the development of recurrence are summarized in Table 1. The median age was 55 years. Only 3\% of tumors had a histology other than invasive ductal carcinoma. Regarding the TNM stage, advanced nodal status and stage were more common in the recurrence group compared with the recurrence-free group. ER and PgR expression was positive in $70 \%$ and $61 \%$ of the 115 patients, respectively. There were more cases of ER- and PgR-positive cancer in the recurrence-free group than recurrence group. The two groups did not differ significantly in the distributions of HER2 positivity, ki67 expression, or the primary systemic chemotherapy regimen received. More patients in the recurrence-free group received breast conserving surgery compared with those in the recurrence group. The frequencies of the postoperative treatments received, including surgery, chemotherapy, trastuzumab, and hormonal therapy, were significantly different between the groups. 
Table 1

Clinicopathological characteristics of 115 breast cancer patients who received neoadjuvant chemotherapy

\begin{tabular}{|c|c|c|c|c|c|c|c|}
\hline & $\begin{array}{l}\text { All p } \\
115)\end{array}$ & ients $(n=$ & $\begin{array}{l}\operatorname{Rec} \\
(n=\end{array}$ & ce-free group & & nce group (n & $P$ value \\
\hline Median age: years ( $r$ & ange) & & & & & & $\begin{array}{l}P= \\
0.72\end{array}$ \\
\hline & 55 & $(32-87)$ & 55 & $(40-87)$ & 56 & $(32-76)$ & \\
\hline Histology: n (\%) & & & & & & & $P=1.0$ \\
\hline IDC & 111 & $(97 \%)$ & 87 & (97\%) & 24 & $(96 \%)$ & \\
\hline Other & 4 & $(3 \%)$ & 3 & $(3 \%)$ & 1 & $(4 \%)$ & \\
\hline Tumor stage: n (\%) & & & & & & & $\begin{array}{l}P= \\
0.10\end{array}$ \\
\hline $\mathrm{T} 1$ & 10 & $(9 \%)$ & 8 & $(9 \%)$ & 2 & $(8 \%)$ & \\
\hline $\mathrm{T} 2$ & 85 & $(74 \%)$ & 70 & $(78 \%)$ & 15 & $(60 \%)$ & \\
\hline T3 & 10 & $(9 \%)$ & 7 & $(8 \%)$ & 3 & $(12 \%)$ & \\
\hline $\mathrm{T} 4$ & 10 & $(9 \%)$ & 5 & $(6 \%)$ & 5 & $(20 \%)$ & \\
\hline Nodal status: n (\%) & & & & & & & $\begin{array}{l}P= \\
0.01\end{array}$ \\
\hline NO & 23 & $(20 \%)$ & 20 & $(22 \%)$ & 3 & $(12 \%)$ & \\
\hline N1 & 71 & $(62 \%)$ & 56 & $(62 \%)$ & 15 & $(60 \%)$ & \\
\hline $\mathrm{N} 2 \mathrm{~A}$ & 9 & $(8 \%)$ & 9 & $(10 \%)$ & 0 & $(0 \%)$ & \\
\hline N2B & 1 & $(1 \%)$ & 0 & $(0 \%)$ & 1 & $(4 \%)$ & \\
\hline N3A & 3 & $(3 \%)$ & 1 & $(1 \%)$ & 2 & $(8 \%)$ & \\
\hline $\mathrm{N} 3 \mathrm{C}$ & 8 & $(7 \%)$ & 4 & $(4 \%)$ & 4 & $(16 \%)$ & \\
\hline Stage: n (\%) & & & & & & & $\begin{array}{l}P= \\
0.10\end{array}$ \\
\hline 1 & 1 & $(1 \%)$ & 1 & $(1 \%)$ & 0 & (0\%) & \\
\hline $2 \mathrm{~A}$ & 25 & $(22 \%)$ & 20 & $(22 \%)$ & 5 & $(20 \%)$ & \\
\hline $2 B$ & 56 & $(49 \%)$ & 47 & $(52 \%)$ & 9 & $(36 \%)$ & \\
\hline $3 A$ & 13 & $(11 \%)$ & 11 & $(12 \%)$ & 2 & (8\%) & \\
\hline $3 B$ & 9 & $(8 \%)$ & 6 & $(7 \%)$ & 3 & $(12 \%)$ & \\
\hline
\end{tabular}

ER, estrogen receptor; PgR, progesterone receptor; HER2, human epidermal growth factor receptor 2 


\begin{tabular}{|c|c|c|c|c|c|c|c|}
\hline \multirow[b]{2}{*}{$3 C$} & \multicolumn{2}{|c|}{$\begin{array}{l}\text { All patients }(n= \\
115)\end{array}$} & \multicolumn{2}{|c|}{$\begin{array}{l}\text { Recurrence-free group } \\
(n=90)\end{array}$} & \multicolumn{2}{|c|}{$\begin{array}{l}\text { Recurrence group ( } \mathrm{n} \\
=25 \text { ) }\end{array}$} & \multirow[t]{2}{*}{$P$ value } \\
\hline & 11 & $(10 \%)$ & 5 & $(6 \%)$ & 6 & $(24 \%)$ & \\
\hline ER status: n (\%) & & & & & & & $\begin{array}{l}P= \\
0.01\end{array}$ \\
\hline+ & 81 & $(70 \%)$ & 68 & $(76 \%)$ & 13 & $(52 \%)$ & \\
\hline- & 34 & $(30 \%)$ & 22 & $(24 \%)$ & 12 & $(48 \%)$ & \\
\hline PgR status: n (\%) & & & & & & & $\begin{array}{l}P= \\
0.01\end{array}$ \\
\hline+ & 70 & $(61 \%)$ & 60 & $(67 \%)$ & 10 & $(40 \%)$ & \\
\hline- & 45 & $(39 \%)$ & 30 & $(33 \%)$ & 15 & $(60 \%)$ & \\
\hline HER2 status: n (\%) & & & & & & & $P=1.0$ \\
\hline+ & 37 & $(32 \%)$ & 29 & $(32 \%)$ & 8 & $(32 \%)$ & \\
\hline- & 78 & $(68 \%)$ & 61 & $(68 \%)$ & 17 & $(68 \%)$ & \\
\hline Ki67 score: n (\%) & & & & & & & $\begin{array}{l}P= \\
0.57\end{array}$ \\
\hline$<14$ & 22 & $(19 \%)$ & 16 & $(18 \%)$ & 6 & $(24 \%)$ & \\
\hline$\geq 14$ & 92 & $(81 \%)$ & 73 & $(82 \%)$ & 19 & $(76 \%)$ & \\
\hline Neoadjuvant chemo & herap & n (\%) & & & & & $P=1.0$ \\
\hline Anthra/taxane & 101 & $(88 \%)$ & 79 & $(88 \%)$ & 22 & $(88 \%)$ & \\
\hline Other & 14 & $(12 \%)$ & 11 & $(12 \%)$ & 3 & $(12 \%)$ & \\
\hline Surgery: n (\%) & & & & & & & $\begin{array}{l}P= \\
0.045\end{array}$ \\
\hline Lumpectomy & 34 & $(30 \%)$ & 31 & (34\%) & 3 & $(12 \%)$ & \\
\hline Mastectomy & 81 & $(70 \%)$ & 59 & $(66 \%)$ & 22 & $(88 \%)$ & \\
\hline Postoperative chem & therap & : n (\%) & & & & & $\begin{array}{l}P< \\
0.001\end{array}$ \\
\hline Yes & 7 & $(6 \%)$ & 1 & $(1 \%)$ & 6 & $(24 \%)$ & \\
\hline No & 108 & $(94 \%)$ & 89 & $(99 \%)$ & 19 & $(76 \%)$ & \\
\hline Postoperative trastu & umab & (\%) & & & & & $\begin{array}{l}P= \\
0.034\end{array}$ \\
\hline
\end{tabular}

ER, estrogen receptor; PgR, progesterone receptor; HER2, human epidermal growth factor receptor 2 


\begin{tabular}{|c|c|c|c|c|c|c|c|}
\hline \multirow[b]{2}{*}{ Yes } & \multicolumn{2}{|c|}{$\begin{array}{l}\text { All patients }(n= \\
115)\end{array}$} & \multicolumn{2}{|c|}{$\begin{array}{l}\text { Recurrence-free group } \\
(\mathrm{n}=90)\end{array}$} & \multicolumn{2}{|c|}{$\begin{array}{l}\text { Recurrence group ( } \mathrm{n} \\
=25 \text { ) }\end{array}$} & \multirow[t]{2}{*}{$P$ value } \\
\hline & 13 & $(11 \%)$ & 7 & $(8 \%)$ & 6 & $(24 \%)$ & \\
\hline No & 102 & (89\%) & 83 & $(92 \%)$ & 19 & $(76 \%)$ & \\
\hline \multicolumn{5}{|c|}{ Postoperative hormones: $\mathrm{n}(\%)$} & & & $\begin{array}{l}P= \\
0.013\end{array}$ \\
\hline Yes & 80 & $(70 \%)$ & 68 & $(75 \%)$ & 12 & $(48 \%)$ & \\
\hline No & 35 & $(30 \%)$ & 22 & $(25 \%)$ & 13 & $(52 \%)$ & \\
\hline
\end{tabular}

The association between the NLR and disease-free survival is shown in Fig. 1. There was no relationship between the NLR and disease-free survival time. We then stratified the patients according to a NLR cutoff of 2.5 , which was selected based on previous studies $[11,14]$. The disease-free survival curves, determined by the Kaplan-Meier method, did not differ significantly according to this NLR cutoff (Fig. 2). This lack of an association remained when a NLR cutoff of 2.0 or 3.0 was used (data not shown).

A Cox proportional hazards model was used to identify prognostic factors significantly associated with disease-free survival (Table 2). We assessed the NLR, disease stage, and ER status as variables; other factors including nodal status, PgR status, and surgical and postoperative treatments received were excluded from the analysis to avoid multicollinearity. The results indicated that the NLR was not associated with disease-free survival (hazard ratio [HR], 0.84; 95\% confidence interval [Cl], 0.65-1.09; $\mathrm{P}=$ 0.19). On the other hand, advanced stage (IIIB-IIIC; HR, 3.11; 95\% $\mathrm{Cl}, 1.35-7.2 ; \mathrm{P}<0.01$ ) and a negative ER status (HR, 2.76; 95\% Cl, 1.23-6.22; $\mathrm{P}=0.01)$ were associated with shorter disease-free survival. 
Table 2

Cox proportional hazards model of prognostic factors associated with disease-free survival

\begin{tabular}{|c|c|c|}
\hline & $\mathrm{HR}(95 \% \mathrm{Cl})$ & $P$ value \\
\hline ER status & & $P=0.01$ \\
\hline+ & 1 & \\
\hline- & $2.76(1.23-6.22)$ & \\
\hline Stage & & $P<0.01$ \\
\hline I-IIIA & 1 & \\
\hline$\| I I B-I I I C$ & $3.11(1.35-7.20)$ & \\
\hline NLR & & $P=0.18$ \\
\hline NLR & $0.83(0.64-1.09)$ & \\
\hline
\end{tabular}

\section{Discussion}

We determined that the NLR has little value as a prognostic factor for early-stage breast cancer, based on the finding of no significant relationship between the NLR and disease-free survival among early-stage breast cancer patients treated with neoadjuvant chemotherapy in our institution. On the other hand, classical prognostic factors such as the ER status and TNM stage were significantly associated with disease-free survival.

In patients with metastatic breast cancer, the NLR is a potentially useful predictor of survival. Leucocytes and lymphocytes play a key role in tumor progression via inflammatory reactions [15]. For example, in a mouse model, leucocytes promoted the metastasis of breast cancer cells to the lung [16]. Immune checkpoint inhibitors, such as atezolizumab, have been used to regulate lymphocytes and prevent tumor progression [17]. Therefore, the NLR and other inflammatory markers may predict an increased risk of cancer mortality in patients with advanced-stage breast cancer, as supported by the findings of a largescale registry study [18].

On the other hand, the value of the NLR as a predictor of survival is controversial in early-stage breast cancer patients. It is questionable whether the small amount of breast cancer at earlier stages affects the systemic immune system. Some reports [9-12], including a meta-analysis [8], demonstrated that the NLR is a significant predictor of the prognosis of early-stage breast cancer patients. However, the possibility of selection bias in those studies should be considered. It is likely that many studies that did not identify an association between the NLR and prognosis did not report their negative findings. On the other hand, the 
finding of such an association of the NLR, which is a relatively novel prognostic factor, is more likely to be published.

Our study has several limitations. It was a retrospective study that evaluated a relatively small number of patients and events. Therefore, our study failed to detect any potential small effect of the NLR on survival. However, these limitations do not affect our conclusion.

\section{Conclusions}

We determined that the NLR has little value as a prognostic factor for early-stage breast cancer. The impact of the NLR needs to be investigated in patients with locally advanced or metastatic breast cancer.

\section{Declarations}

\section{Ethics approval and consent to participate}

This study was approved by our institutional ethics board (RK-210112-8). This study was performed in accordance with the principles of the Declaration of Helsinki.

\section{Consent for publication}

Under the regulation of our institutional ethics board, informed consent was obtained in the form of optout system on the web-site. Those who declined were excluded.

\section{Availability of data and materials}

The datasets used and/or analyzed in the current study are available from the corresponding author upon reasonable request.

\section{Competing interests}

The authors declare that they have no competing interests.

\section{Funding}

No source of funding was associated with this study.

\section{Authors' contributions}

$\mathrm{KE}, \mathrm{SF}, \mathrm{HG}, \mathrm{SM}$, and $\mathrm{YH}$ collected the data, and all authors contributed to drafting the manuscript. All authors read and approved the final manuscript.

\section{Acknowledgements}


We thank Mieko Nishikiori and Yuka Suzuki for their administrative assistance.

\section{References}

1. Bray F, Ferlay J, Soerjomataram I, Siegel RL, Torre LA, Jemal A. Global cancer statistics 2018: GLOBOCAN estimates of incidence and mortality worldwide for 36 cancers in 185 countries. CA Cancer J Clin. 2018;68:394-424.

2. Citron ML, Berry DA, Cirrincione C, Hudis C, Winer EP, Gradishar WJ, Davidson NE, Martino S, Livingston $\mathrm{R}$, Ingle $\mathrm{JN}$, et al. Randomized trial of dose-dense versus conventionally scheduled and sequential versus concurrent combination chemotherapy as postoperative adjuvant treatment of node-positive primary breast cancer: first report of Intergroup Trial C9741/Cancer and Leukemia Group B Trial 9741. J Clin Oncol. 2003;21:1431-9.

3. Crump M, Tu D, Shepherd L, Levine M, Bramwell V, Pritchard K. Risk of acute leukemia following epirubicin-based adjuvant chemotherapy: a report from the National Cancer Institute of Canada Clinical Trials Group. J Clin Oncol. 2003;21:3066-71.

4. Paik S, Tang G, Shak S, Kim C, Baker J, Kim W, Cronin M, Baehner FL, Watson D, Bryant J, et al. Gene expression and benefit of chemotherapy in women with node-negative, estrogen receptor-positive breast cancer. J Clin Oncol. 2006;24:3726-34.

5. Kishi Y, Kopetz S, Chun YS, Palavecino M, Abdalla EK, Vauthey JN. Blood neutrophil-to-lymphocyte ratio predicts survival in patients with colorectal liver metastases treated with systemic chemotherapy. Ann Surg Oncol. 2009;16:614-22.

6. Yamanaka T, Matsumoto S, Teramukai S, Ishiwata R, Nagai Y, Fukushima M. The baseline ratio of neutrophils to lymphocytes is associated with patient prognosis in advanced gastric cancer. Oncology. 2007;73:215-20.

7. Sarraf KM, Belcher E, Raevsky E, Nicholson AG, Goldstraw P, Lim E. Neutrophil/lymphocyte ratio and its association with survival after complete resection in non-small cell lung cancer. J Thorac Cardiovasc Surg. 2009;137:425-8.

8. Duan J, Pan L, Yang M. Preoperative elevated neutrophil-to-lymphocyte ratio (NLR) and derived NLR are associated with poor prognosis in patients with breast cancer: A meta-analysis. Medicine. 2018;97:e13340.

9. Cho U, Park HS, Im SY, Yoo CY, Jung JH, Suh YJ, Choi HJ. Prognostic value of systemic inflammatory markers and development of a nomogram in breast cancer. PLoS One. 2018;13:e0200936.

10. Geng SK, Fu SM, Fu YP, Zhang HW. Neutrophil to lymphocyte ratio is a prognostic factor for disease free survival in patients with breast cancer underwent curative resection. Medicine. 2018;97:e11898.

11. Nakano K, Hosoda M, Yamamoto M, Yamashita H. Prognostic significance of pre-treatment neutrophil: Iymphocyte ratio in Japanese patients with breast cancer. Anticancer Res. 2014;34:381924. 
12. Azab B, Bhatt VR, Phookan J, Murukutla S, Kohn N, Terjanian T, Widmann WD. Usefulness of the neutrophil-to-lymphocyte ratio in predicting short- and long-term mortality in breast cancer patients. Ann Surg Oncol. 2012;19:217-24.

13. Takeuchi H, Kawanaka H, Fukuyama S, Kubo N, Hiroshige S, Yano T. Comparison of the prognostic values of preoperative inflammation-based parameters in patients with breast cancer. PLoS One. 2017;12:e0177137.

14. Guthrie GJ, Charles KA, Roxburgh CS, Horgan PG, McMillan DC, Clarke SJ. The systemic inflammation-based neutrophil-lymphocyte ratio: experience in patients with cancer. Crit Rev Oncol Hematol. 2013;88:218-30.

15. Balkwill F, Mantovani A. Inflammation and cancer: back to Virchow? Lancet 2001, 357:539-545.

16. Wculek SK, Malanchi I. Neutrophils support lung colonization of metastasis-initiating breast cancer cells. Nature. 2015;528:413-7.

17. Schmid P, Adams S, Rugo HS, Schneeweiss A, Barrios CH, Iwata H, Dieras V, Hegg R, Im SA, Shaw Wright G, et al. Atezolizumab and Nab-Paclitaxel in Advanced Triple-Negative Breast Cancer. N Engl J Med. 2018;379:2108-21.

18. Proctor MJ, Morrison DS, Talwar D, Balmer SM, O'Reilly DS, Foulis AK, Horgan PG, McMillan DC. An inflammation-based prognostic score (mGPS) predicts cancer survival independent of tumour site: a Glasgow Inflammation Outcome Study. Br J Cancer. 2011;104:726-34.

\section{Figures}




\section{DFS and NLR}

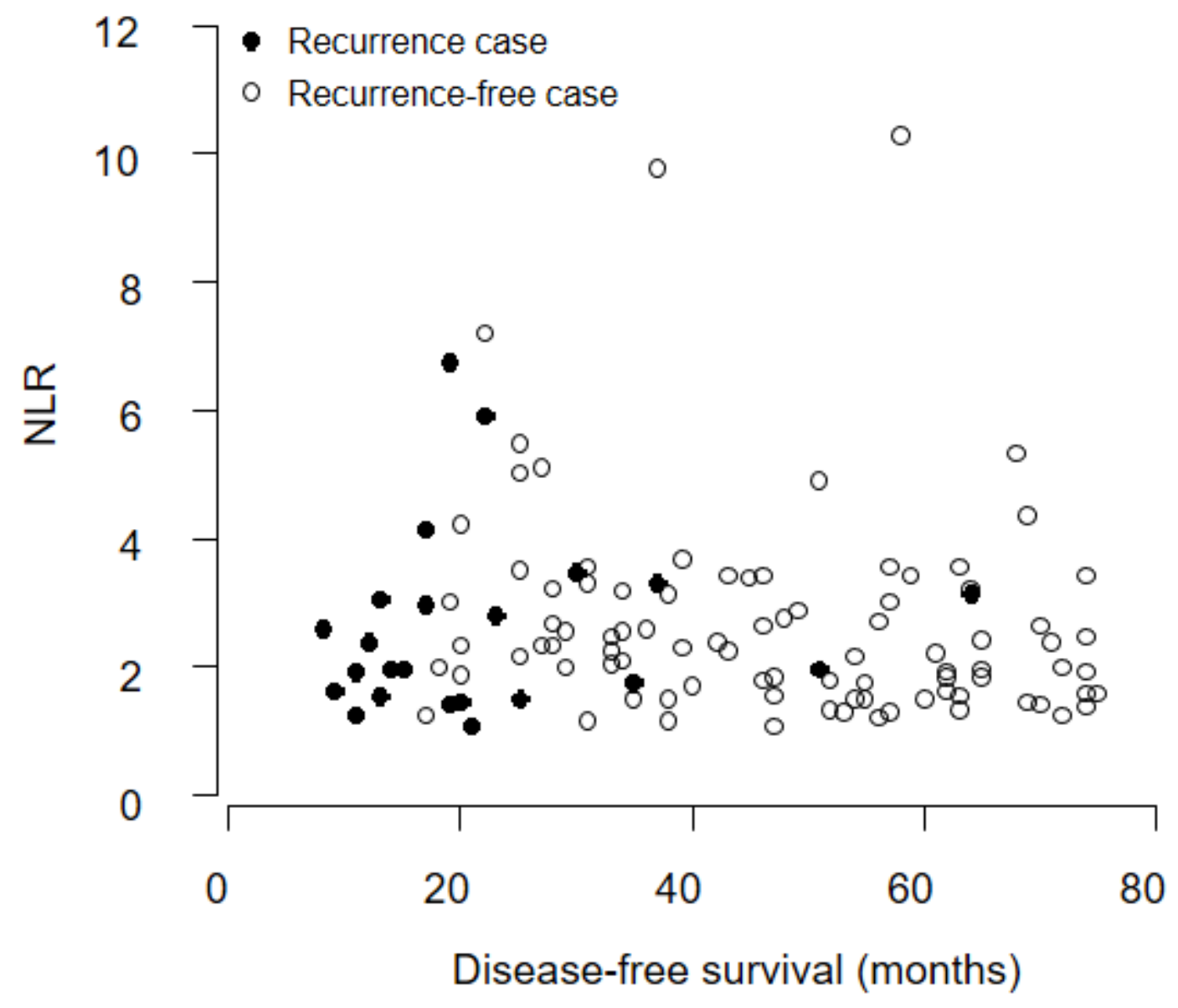

Figure 1

A plot of the disease-free survival time versus the NLR of each patient. The solid and empty circles denote the patients with and without recurrence, respectively. No significant association between the NLR and disease-free survival was found. 


\section{DFS stratified by NLR of 2.5}

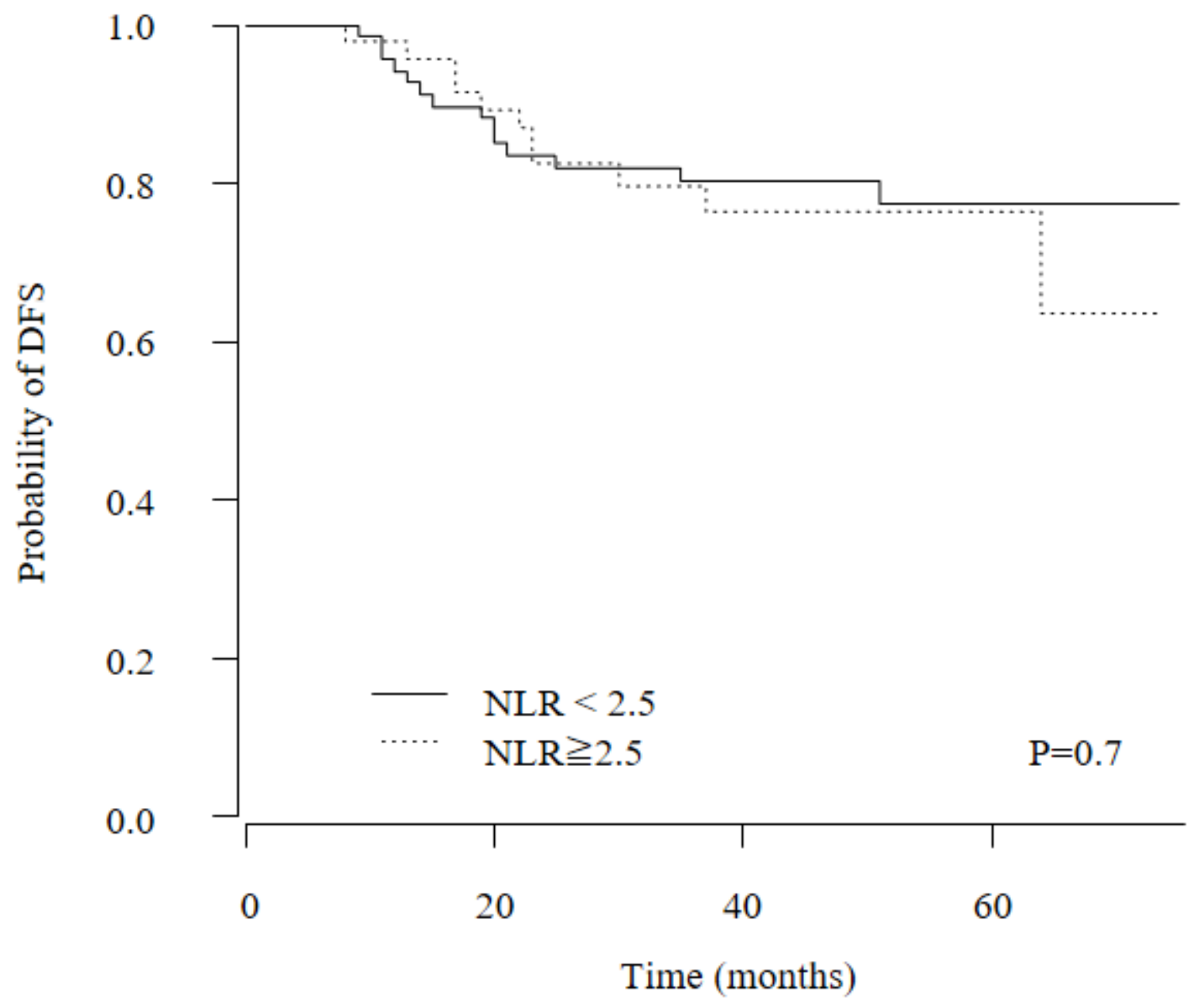

Figure 2

Kaplan-Meier disease-free survival curves stratified by a NLR cutoff of 2.5. There was no significant difference in disease-free survival according to the NLR. 